\title{
Association Between Smart Phones Usage and Children Behaviour Change
}

\author{
S Shreenidhi', S. Leslie Rani², Brundha M. P2* \\ ${ }^{1} S$ Shreenidhi Saveetha Dental College and Hospitals Saveetha Institute \\ of Medical and Technical Science, Saveetha University. Chennai, India \\ ${ }^{2}$ Lecturer, Department of Pathology, Saveetha dental college and hospital, Saveetha \\ Institute of Medical and Technical Science, Saveetha University Chennai, India \\ ${ }^{2 *}$ Associate professor,Department of Pathology Saveetha Dental College And Hospital Saveetha \\ Institute of Medical and Technical Science, Saveetha University. Chennai, India
}

\section{ABSTRACT}

Smartphone usage has become widely increased since the past decade and has captured the eyes of many young growing children who fall precisely under the age group of 15 years and below. The over usage of the gadgets (smart phones) have prone to be a hazardous effect on them in changing the mental and physical state. This study was conducted in order to associate the smartphone usage and children's behavioral change and also to bring about awareness among the parents of the dangerous outcome provided due to prolonged usage of smartphones among the younger generation of kids. A set of questionnaires were developed and circulated among parents of children under different age groups were categorized into Group I (6- 10 years) and Group II (11-15 years) in relation to behavioural changes associated with the usage of smartphones. A total 100 responses were collected and analyzed through SPSS software and Chi square test was done. The study concludes that parents found that children were very much addicted towards usage of smartphones and found behavioural changes in them and there is a significant difference between the Group I parents and Group II parents though they perform very good in academics with the help of learning through study apps they had eye related health problems and often throw tantrums when the smartphones are being snatched away from them. The study also includes that parents must be aware of the effects caused by over usage of smartphones among the younger generation, in order to minimize the level of usage..

KEY WORDS: MOBILES, OVER USAGE,MENTAL WELL BEING, LOW CONFIDENCE, CONCENTRATION.

\section{INTRODUCTION}

The development of mobile phones in recent times is found to produce smartphone addiction. The prevalence of smartphone addiction increases day by day. It causes

\section{ARTICLE INFORMATION}

${ }^{*}$ Corresponding Author: brundha.sdc@saveetha.com Received 10th June 2020 Accepted after revision 8th August 2020 Print ISSN: 0974-6455 Online ISSN: 2321-4007 CODEN: BBRCBA

Thomson Reuters ISI Web of Science Clarivate Analytics USA and Crossref Indexed Journal

\section{Clarivate}

crossef

NAAS Journal Score 2020 (4.31) SJIF: 2020 (7.728)

A Society of Science and Nature Publication,

Bhopal India 2020. All rights reserved.

Online Contents Available at: http//www.bbrc.in/

Doi: $h$ ttp://dx.doi.org/10.21786/bbrc/13.7/13 psychological and behavioral dependence(Panova and Carbonell, 2018). Studies show chronic smartphone users are affected with headaches, impaired memory and concentration, fatigue, dizziness and disturbed sleep(AlKhlaiwi and Meo, 2004). It also stated that, some people may develop electrosensitivity from excessive exposure to electromagnetic fields.Although these symptoms may be primarily psychological in origin due to the nocebo effect(Carpenter, 2014).The psychological symptoms of the people who are addicted to smartphones might possess depression.Depression is a medical illness that adversely influences people in emotion, imagination, and action(Zwanenburg, no date). 
Children are most affected among all the age groups. Nowadays, children are spending more time-with smart phones-which reduces their learning and play time. It is also noted that doctors and educators are worried about the impact of overexposure to touchscreen technology in developing brains. Mobile phones primarily function on electromagnetic waves for all forms of communication(Frey, 1962). The brain has its own electric impulses and communication is carried out in the neural network. In children, the waves from the phone can easily penetrate right into the brain, as they do not have a strong shield.Research has shown that by merely talking on the phone for 2 minutes, the electrical activity inside a child's brain can be changed. This erratic activity can cause changes in mood patterns and behavioral changes and children may have trouble learning new things or focusing properly on studies(Ting and Chen, 2020).

Unstrained use of technology or smart phones has an effect on children's development both in social and physical well being and result in symptoms related to other behavioral addiction(Ryding and Kaye, 2018). Unrestricted use of technological devices among children are prone to have effect on development due to lack of recognition and consensus of concepts(Cha and Seo, 2018).A survey done by a group of researchers-relieved that $43 \%$ of people underage of 15 years experiences anxiety and even irritation when they are not able to access phones when they want(Walker, 2019). Recent studies have also found association between behavioral changes in children in relation with using smart phones for a longer duration of time(Hawi and Samaha, 2016). Also over the past decade there has been an increase in smartphone usage among children(Tinkler, 2015) resulting in increased rise of common mental and physical health related problems(Han et al., 2017).

The current study is conducted among a group of parents having children under the age group of 15 years, to assess the usage level of smart phones by their children, the factors influencing the behavior and the impact of smartphone usage in their academic performance.

\section{MATERIAL AND METHODS}

A cross- sectional questionnaire survey was conducted to parents of children below 15 years Questions are set on two levels. First set of questions were based on demographic data including age, sex, class of study, education level and occupation of parents, etc. Second set of questions were based on their social behavior, academic performance, intellectual thinking, physical activity, etc. Children belonging to the age group above 15 years and physically challenged are excluded from the study. The questionnaire containing 20 questions were circulated to the parents. The data was collected and further analysed using SPSS software and Chi square test was done. The results are given in the form of percentages and depicted in bar graphs. For better understanding the study population was split into two groups, group 1 parents with children between the age of 6-10 years and group 2 of parents with children between the age of 1115 years .The obtained results are statistically analyzed and charts were prepared.

\section{RESULTS AND DISCUSSION}

Prevalence of exposure to cell phones to young children is increasing day by day (Divan et al., 2012). Single children and parents are becoming more addicted to smartphone usage as they don't have a better companion to play. In most nuclear families, both parents are going to work and they don't have much time to spend with their children. This makes their children lonely and becomes addicted to smartphones. Figure 1 shows the class studied by the children participating in the study. Among 100 participants, out of which 23\% of their children are from 1st grade class, 21\% of their children were from other grades that fall in the category of above the age of 15 years.Figure 2 shows that students though are seen in with handling smart phones for a very long time, $60 \%$ of them have scored good performance in academics thus the results of data show that smart phones though being used widely by younger generation for a long period of time, they were able to show a great significant effect in their academic performance. There are certain education apps that have been introduced to make the difficult subject easier. Even if they miss their class or are absent from their class, they follow the apps and study.

Figure 1: Bar graph depicting the responses collected for the question to what class their children are studying. Where $\mathrm{X}$ axis represents the grade and $\mathrm{Y}$ axis represents the number of responses for which $12 \%$ responded kindergarten, $17 \%$ for 2 nd grade, $30 \%$ for 1 st grade, $16 \%$ for 3 rd grade, $10 \%$ for 4 th grade, $4 \%$ for 5 th grade and $11 \%$ for 6 th grade

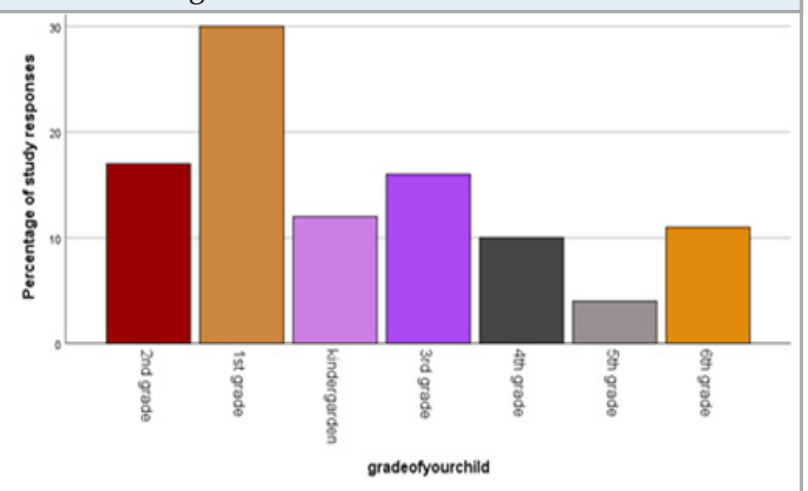

Smart phones provide a variety of gateway to children in whiling away their time that is to be spent among with friends and neighbors. According to this study, it shows that $70 \%$ of children are isolated from their friends and neighbors due to the addiction of smartphones, while the rest 30\% do not prefer to play with neighbors and friends (Figure 3). There are many game apps which engage the children for many hours.Smartphones affect the communication and emotional stability of a child, if a child is dependent on a smartphone to express their 
feelings they risk weakening their communication skill. According to the results, 60\% of their parents agree saying that children show temper tantrums when phones are being snatched away from them while 40\% of them do not show any kind of behavioral change while their phones are being snatched away from them (Figure 4).

Figure 2: Bar graph depicting the responses for the question whether their children are good at studies. Where the $\mathrm{X}$ axis represents the options and $\mathrm{Y}$ axis represents the options for which $60 \%$ stated yes(red) and $40 \%$ stated that their children were not good in studies (blue)

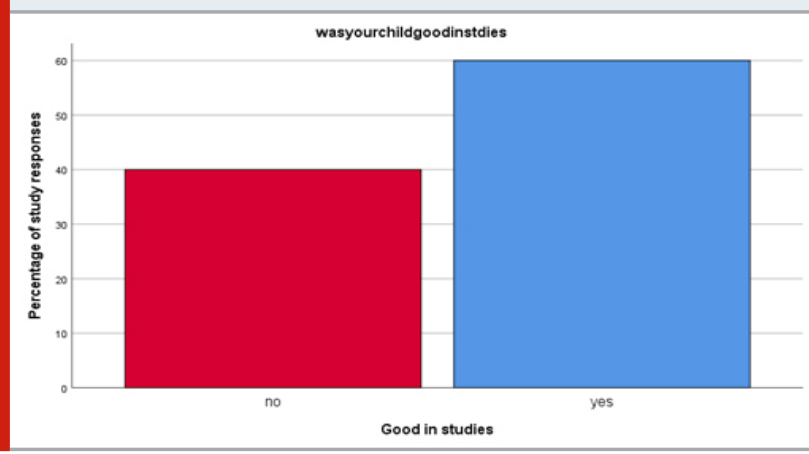

Figurer 3: Bar graph depicting the responses for questions for which parents were asked if smart phones isolate your children from neighbors and friends. Where $\mathrm{X}$ axis represents options and $\mathrm{Y}$ axis represents the responses for which $70 \%$ of the parents stated yes and $20 \%$ of the parents stated no

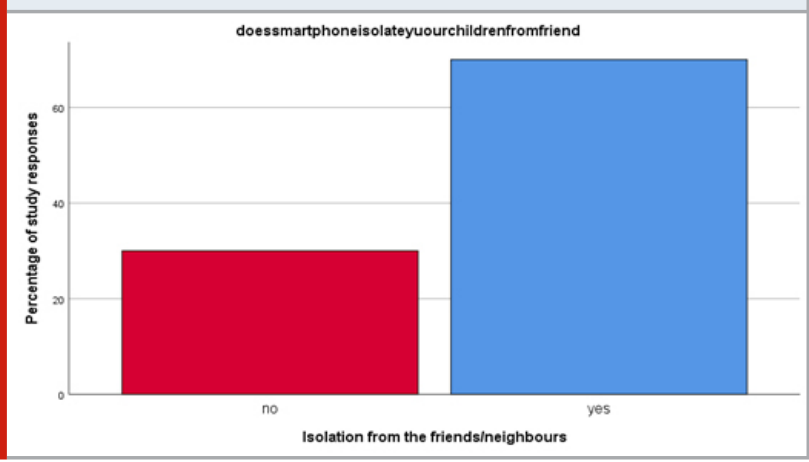

Figure 4: Bar graph depicting the responses collected for the question whether their children shows temper tantrums when the phones are fetched away where $\mathrm{X}$ axis represents the options and $\mathrm{Y}$ axis represents the options for which $60 \%$ stated yes and $40 \%$ stated no

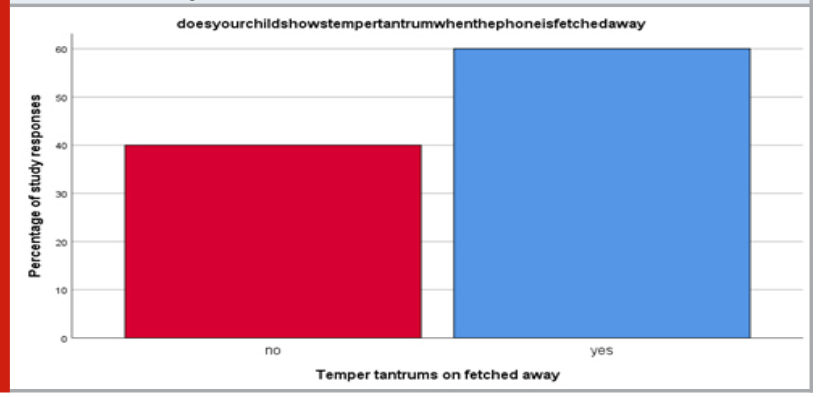

The smartphone usage is highly noted during the leisure time, in which 38\% of parents have stated that children prefer playing outside with their fellow mates, while the majority of children (41\%) play with their smartphones and 21\% prefer sleeping in their free time as shown in figure 5. Smart phones are being widely used among children for the main usage of apps that are being downloaded for their own purposes of happiness, according to the study conducted frequently used apps among children are majority of $44 \%$ of children most commonly use it for studying and learning conceptual based videos to understand and for better learning, while $38 \%$ of them use it for gaming and the rest 18\% use it for social media pleasure as shown in Figure 6.

Figure 5: Bar graph depicting the results collected on what will their kids do at their free time where $\mathrm{X}$ axis represents the options and $\mathrm{Y}$ axis represents the responses for which $39 \%$ opted outdoor games, $40 \%$ opted on playing with smart phones and 21\% opted for others such as sleeping or staying indoor

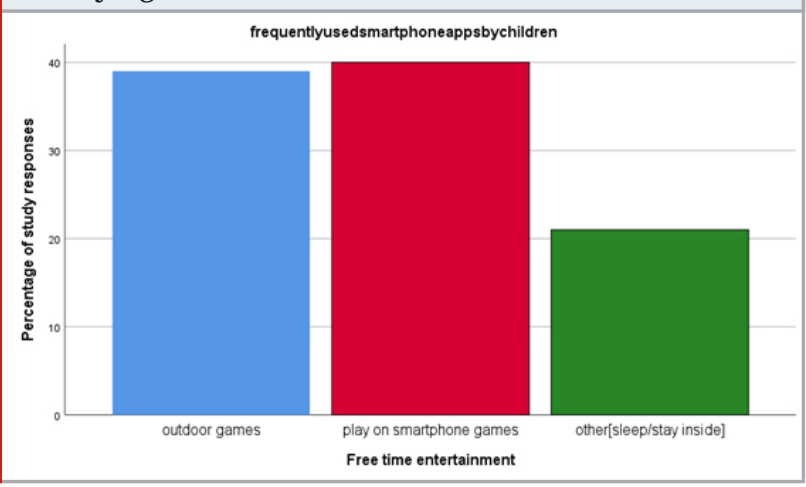

Figure 6: Bar graph depicting the responses collected for frequently used smartphone apps by their children where $\mathrm{X}$ axis represents the options and $\mathrm{Y}$ axis represents the number of responses for which $39 \%$ opted for gaming apps, $44 \%$ on study apps and $17 \%$ on social media

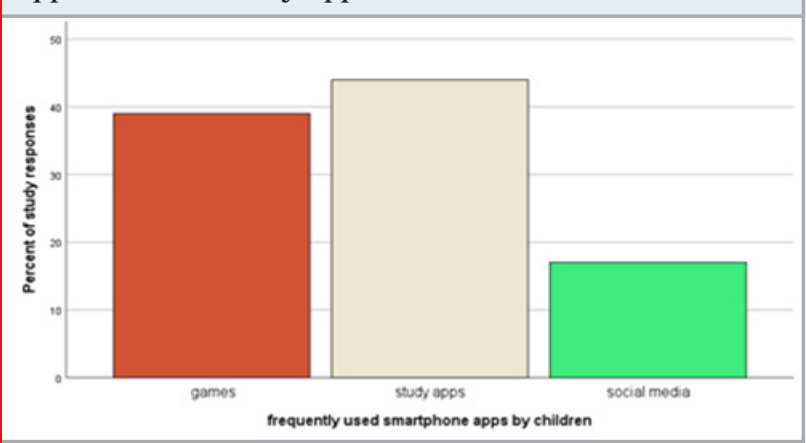

Usage of smartphones have been highly notable and the respective outcomes have also seen negative outcomes. From figure7, it shows that majority of the children (40\%) were suffering from eye problem due to prolonged usage of smart phones than the required time of use, $30 \%$ of children suffer from head aches due to long time exposure of the eyes that are strained more during use age of smart phones and the rest 30\% are obese since they spend more time in playing and watching over 
phones in their leisure time rather than playing outside with their friends.

Figure 7: Bar graph depicting the responses collected on whether the child has any of the following health related problems where $\mathrm{X}$ axis represents the options and $\mathrm{Y}$ axis represents the number of responses for which $40 \%$ opted eye problems, 30\% opted headaches and 30\% opted obesity

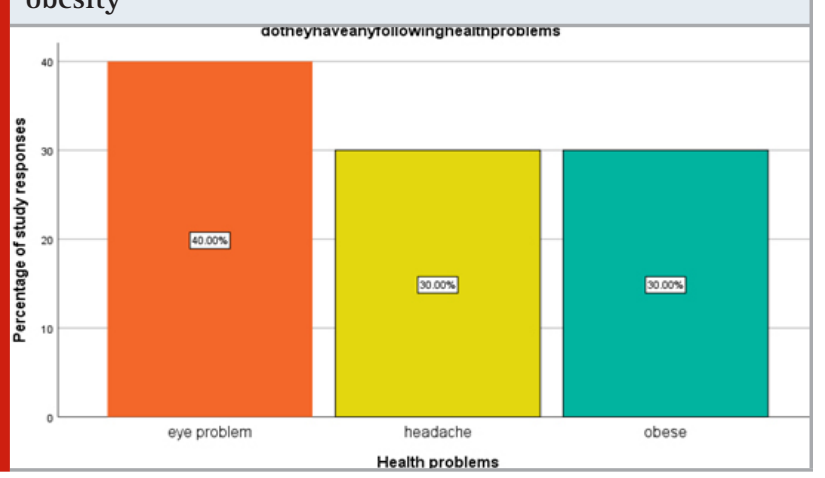

Figure 8 shows the majority of the parents of children between 6-10 years observed the behavioural changes in their children when snatching away the smart phones than the parents of children aged between 11 - 15 years and the difference was also significant statistically(p value- $0.00<0.05)$. Figure 9 shows the majority of the parents of children between 6-10 years observed that their children frequently use games apps than the other games and that was higher than parents of children between 11-15 years(opt for study apps) and the difference was also significant statistically(p value $0.000(<0.05))$.Figure 10 shows the majority of the group 2 parents observed that their children were isolated from the friends and neighbours than the group 1 parents. There was a significant difference found in association between parents groups and their behavioral changes (p value- $0.00<0.05$ )

Figure 8: Bar graph showing association between parent group and their child's behavior when the phone is being snatched away. $\mathrm{X}$ axis represents the parent group and $\mathrm{Y}$ axis represents the responses. Majority of the parents of children between 6-10 years observed the behavioural changes in their children when snatching away the smart phones than the parents of children aged between $11-15$ years and the difference was also significant statistically. Pearson chi square test was done; $p$ value- $0<0.05$.

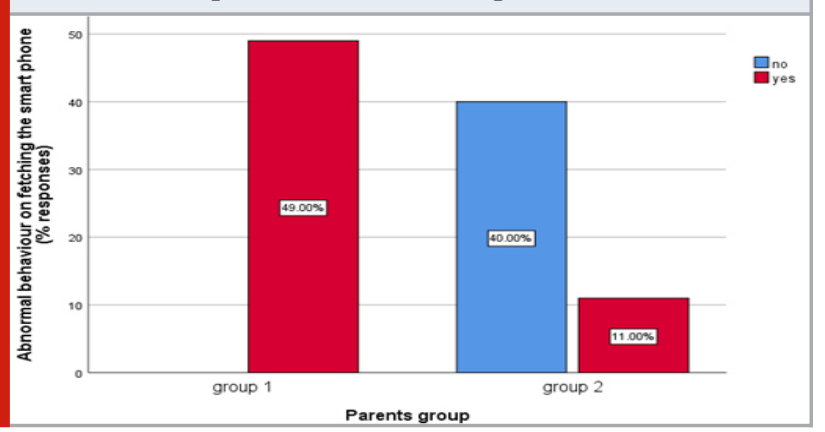

Figure 9: Bar graph showing association between parents group and the frequently used apps. $\mathrm{X}$ axis represents the parent group and the $\mathrm{Y}$ axis represents the responses. Majority of the parents of children between 6-10 years observed that their children frequently use games apps than the other games and that was higher than parents of children between 11-15 years(opt for study apps) and the difference was also significant statistically. Pearson Chi-square test was done; $p$ value $0.000(<0.05)$.

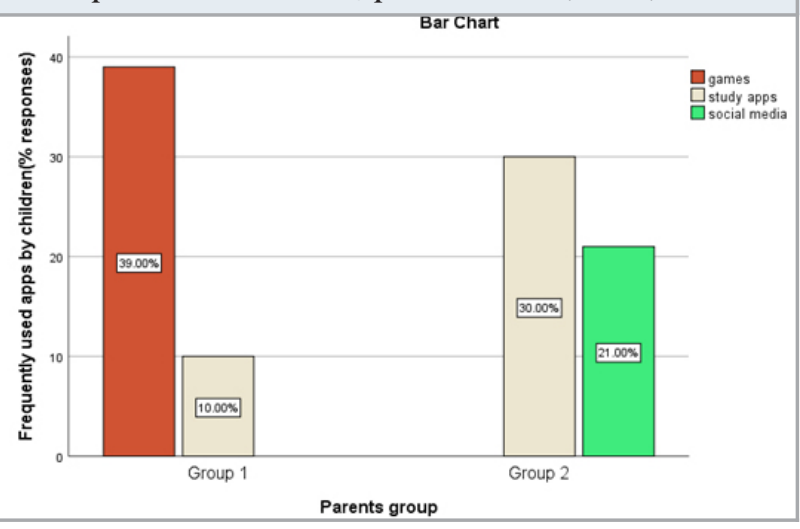

Figure 10: Bar graph showing association between parents group and whether the smart phone isolates their children from their friends and neighbors. $\mathrm{X}$ axis represents the parents group and $\mathrm{Y}$ axis represents the options. Majority of the group 2 parents observed that their children were isolated from the friends and neighbours than the group 1 parents. There was a significant difference found in association between parents groups and their behavioral changes. Pearson Chi-square test was done; $p$ value$0<0.05$

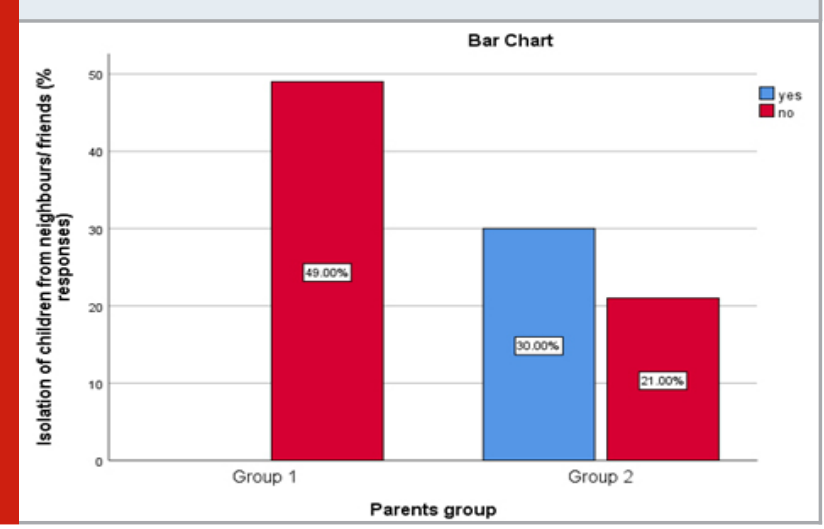

Through this study it can be concluded that children were showing good academic performance. But their social behavior and physical activity are declining gradually. Prolonged usage of smartphones also has some negative impact on their health. Few are suffering from eye problems and some encounter headaches. Chronic addiction to smartphones makes the children lazy and they don't prefer outdoor games. This affects their health. Inadequate physical activity make them obese and lethargic. As this study is a pilot study with 100 responses, we cannot conclude that smartphones 
promote their performance in academic studies, because the chosen population are below 15 years of age. Further study must be conducted to assess the prevalence of addiction to smartphones among school going children of various ages.

\section{CONCLUSION}

Thereby the study concludes that smart phones usage is more among the children under 6-10years for the purpose majorly than the children of 11-15 years. The parents of children aged 11-15 years observed that their children were isolated from their friends and neighbours because of constant smartphone usage than parents of children aged 6-10 years. All observed the temper tantrums among their children while snatching away the smartphones. From this study, we also found that the majority of the parents are taking utmost care in the child's lives and monitoring the use of phones.

\section{ACKNOWLEDGEMENTS}

We thank Saveetha dental college for the support to carry out this study.

Conflict of Interest: None to declare

\section{REFERENCES}

Al-Khlaiwi, T. and Meo, S. A. (2004) 'Association of mobile phone radiation with fatigue, headache, dizziness, tension and sleep disturbance in Saudi population', Saudi medical journal, 25(6), pp. 732736.

Carpenter, D. 0. (2014) 'Excessive exposure to radiofrequency electromagnetic fields may cause the development of electrohypersensitivity', Alternative therapies in health and medicine, 20(6), pp. 40-42.

Cha, S.-S. and Seo, B.-K. (2018) 'Smartphone use and smartphone addiction in middle school students in
Korea: Prevalence, social networking service, and game use', Health Psychology Open, p. 205510291875504 . doi: 10.1177/2055102918755046.

Divan, H. A. et al. (2012) 'Cell phone use and behavioural problems in young children', Journal of epidemiology and community health, 66(6), pp. 524-529.

Frey, A. H. (1962) 'Human auditory system response to modulated electromagnetic energy', Journal of applied physiology, 17, pp. 689-692.

Han, B. et al. (2017) 'National Trends In Specialty Outpatient Mental Health Care Among Adults', Health affairs , 36(12), pp. 2062-2068.

Hawi, N. S. and Samaha, M. (2016) 'To excel or not to excel: Strong evidence on the adverse effect of smartphone addiction on academic performance', Computers \& Education, pp. 81-89. doi: 10.1016/j. compedu.2016.03.007.

Panova, T. and Carbonell, X. (2018) 'Is smartphone addiction really an addiction?', Journal of Behavioral Addictions, pp. 252-259. doi: 10.1556/2006.7.2018.49.

Ryding, F. C. and Kaye, L. K. (2018) “"Internet Addiction”: a Conceptual Minefield', International journal of mental health and addiction, 16(1), pp. 225-232.

Ting, C. H. and Chen, Y. Y. (2020) 'Smartphone addiction', Adolescent Addiction, pp. 215-240. doi: 10.1016/b978-0-12-818626-8.00008-6.

Tinkler, L. (2015) 'THE OFFICE FOR NATIONAL STATISTICS EXPERIENCE OF COLLECTING AND MEASURING SUBJECTIVE WELL-BEING', Statistics in Transition. New Series, pp. 373-396. doi: 10.21307/ stattrans-2015-021.

Walker, J. (2019) The Negative Impact of Smartphones and Mobile Devices: Comprehensive Overview on the Damaging Adverse Effect of Smart Phone Overuse/ Addiction. Independently Published.

Zwanenburg, S. P. (no date) 'Smartphone addiction ': doi: $10.5353 /$ th_b5793642. 